\title{
The Impact of Circulating Mitochondrial DNA on Cardiomyocyte Apoptosis and Myocardial Injury After TLR4 Activation in Experimental Autoimmune Myocarditis
}

\author{
Bangwei Wu Huanchun Ni Jian Li Xinyu Zhuang Jinjin Zhang Zhiyong Qi \\ Qiying Chen Zhichao Wen Haiming Shi Xinping Luo Bo Jin
}

Department of Cardiology, Huashan Hospital, Fudan University, Shanghai, China

\section{Key Words}

TLR4 • EAM • Circulating mtDNA • ROS stress $\bullet$ TLR9

\begin{abstract}
Background/Aims: Mitochondrial DNA (mtDNA), acting as a newly found 'dangerassociated molecular patterns' (DAMPs), is released into circulation upon tissue injury and performs as a considerable activator of inflammation and immune response. However, the role of circulating mtDNA in experimental autoimmune myocarditis (EAM) as well as Toll like receptor4 (TLR4) mediated cardiac inflammation and injury remains unknown. Methods: $A$ model of EAM was established in BALB/c mice by immunization with porcine cardiac myosin. Lipopolysaccharide (LPS) was used to stimulate TLR4 activation in EAM mice and H9C2 cells. Results: LPS stimulation significantly aggravated cardiac inflammation and tissue injury in EAM, as demonstrated by increased myocardium inflammatory cell infiltration, and upregulated inflammatory cytokines and troponin I(TnI) level in serum. Circulating mtDNA level was increased in EAM and TLR4 activation led to a greater elevation, which may be related to Reactive oxygen species (ROS) stress involved mtDNA damage characterized by reduced mtDNA copy number in myocardium tissue. In addition, the expression of Toll like receptor 9 (TLR9), a ligand of mtDNA, was significantly up-regulated in the myocardium of EAM and EAM LPS group; meanwhile, TLR9 inhibition by ODN 2088 caused an inhibited apoptosis in LPS treated H9C2 cells. Moreover, in EAM and EAM LPS group, simultaneously giving ODN 2088 treatment significantly ameliorated cardiac inflammation and tissue injury compared with untreated group. Conclusion: Increased circulating mtDNA combined with upregulated TLR9 expression may corporately play a role in EAM as well as TLR4 activation mediated cardiac inflammation and injury.
\end{abstract}




\section{Cellular Physiology Cell Physiol Biochem 2017;42:713-728 \begin{tabular}{ll|l} 
DOI: 10.1159/000477889 & $\begin{array}{l}\text { O 2017 The Author(s). Published by S. Karger AG, Basel } \\
\text { www.karger.com/cpb }\end{array}$
\end{tabular} Wu et al.: Circulating Mitochondrial DNA in Experimental Autoimmune Myocarditis}

\section{Introduction}

Autoimmune myocarditis, a major cause of dilated cardiomyopathy(DCM), is regarded as a persistent inflammation condition generating severe and irreversible damage to the myocardium, which is triggered by endogenous alarm signals referred to as 'dangerassociated molecular patterns' (DAMPs) [1,2]. These DAMPs are recognized mainly by Tolllike receptors (TLRs) expressing on immune cells and parenchymal cells in heart [3].

TLR4 activation has been demonstrated to be indispensable for the induction of experimental autoimmune myocarditis (EAM), and the development into the phrase of DCM $[4,5]$. TLR4 mediated inflammatory immunity response characteristic with leucocyte activation and infiltration in myocardium leads to cytokine secretion, oxidative stress and protease release, which promotes apoptosis and necrosis of myocardial cells $[1,6]$. Along with this, damaged myocardium could release more endogenous molecules termed DAMPs, including HSPs, HMGB1, crystalline uric acid, fibronectin and mitochondrial component, recognized by TLRs and forming a positive feedback loop to aggravate heart injury and promote DCM formation [2,3]. Besides, knock-out of TLR4 or targeting downstream effectors of TLR4 such as MyD88 showed protective effects in several types of heart failure animal models, namely, myocardial ischemia, pressure overload and autoimmune myocarditis $[4,7,8]$. Taken together, TLR4 activation acts as an important mediator for autoimmune myocarditis, and to clarify the molecular basis of TLR4 functioning in a critical effector pathway is vitally needed for the therapeutic interventions in EAM $[1,5]$.

Recent study has clearly demonstrated that dysfunctional mitochondria are crucial sources of DAMPS [9]. Mitochondrial components including mitochondrial DNA (mtDNA), $\mathrm{N}$-formyl peptides and lipids such as cardiolipin are released into cytoplasm or extracellularly performing as powerful initiators and masters of the innate immune response $[9,10]$. MtDNA, consisting of an approximately $16.5 \mathrm{~kb}$ circular double-stranded extrachromosomal DNA, particularly with an unmethylated CpG motif that resembles bacterial DNA, as a newly found DAMP, shows an increasing role in inflammatory diseases [11, 12]. It was revealed that mtDNA may be released following cellular necrosis and apoptosis [13]; however, studies showed that TLR4 stimulation by LPS can also induce mtDNA secretion in vivo and in vitro $[12,14]$. Circulating mtDNA level was significantly increased in patients with a variety of critical conditions including severe sepsis, trauma and acute ischemia in heart or kidney [15-17]. Several immune cells including monocytes and granulocytes could be activated by mtDNA and present an inflammatory phenotype $[18,19]$. In isolated rat lungs, exogenous administration of mtDNA could recapitulate the clinical phenotype of acute respiratory distress syndrome, which was abrogated by the simultaneous administration of TLR9 blocker [20]. Recently, mtDNA has been discovered to play a growing role in cardiovascular diseases [11]. Damaged mtDNA mediated by oxidative stress induced a potent inflammatory response and promoted atherosclerosis development in the aortas of LDLR knockout mice [21]. McCarthy et al demonstrated that circulating mtDNA contributed to elevated arterial pressure and vascular dysfunction in spontaneously hypertensive rats [22]. Moreover, study also showed that extracellular mtDNA can directly cause mitochondrial dysfunction and death in cardiomyocytes by inducing ROS stress and NF-kB activation [23]. However, the role of mtDNA in EAM has not been investigated.

In the current study, we hypothesized that the level of circulating mtDNA is elevated in EAM, and may involve in TLR4 mediated cardiomyocyte apoptosis and myocardial injury. We observed the changes of mtDNA damage mediated by TLR4 in vivo and in vitro, and explored the possible role of ROS stress in circulating mtDNA level in EAM. Finally, we investigated the effect of TLR9 inhibition with ODN2088 in EAM as well as TLR4 mediated cardiomyocyte apoptosis and myocardial injury. 


\section{Cellular Physiology Cell Physiol Biochem 2017;42:713-728 \begin{tabular}{l|l} 
and Biochemistry Published ondine: June 14, 2017 & $\begin{array}{l}\text { D } 2017 \text { The Author(s). Published by S. Karger AG, Basel } \\
\text { www.karger.com/cpb }\end{array}$
\end{tabular} \\ Wu et al.: Circulating Mitochondrial DNA in Experimental Autoimmune Myocarditis}

\section{Materials and Methods}

Experimental autoimmune myocarditis and experimental design

Male C57BL/6 mice aged 6 weeks were purchased from Animal Experimental Center of Fudan University (Shanghai, China). The mice were treated with a standard diet and water ad libitum at the Shanghai Medical College Animal Care Facility according to institutional guidelines. For EAM induction, mice were immunized with $200 \mathrm{uL}$ of a 1:1 emulsion of PBS with $2 \mathrm{mg} / \mathrm{mL}$ of porcine cardiac myosin (Sigma Chemical Co) in complete Freund's adjuvant (CFA) (Sigma) in the groin subcutaneously at days 0 and 7 as described previously [24]. Control mice received PBS/CFA only. The EAM animals were randomly allocated to five groups as follows: EAM group received $200 \mu \mathrm{l}$ normal saline; EAM LPS group received LPS $(2.5 \mathrm{mg} / \mathrm{kg}$ ) (Invivogen, San Diego, CA, USA) (dissolved in $200 \mu \mathrm{l}$ normal saline); EAM+ODN Control group received ODN Control (50ug/20g) (Invivogen); EAM+ODN 2088 group received ODN 2088 (50ug/20g) (Invivogen); EAM LPS+ODN 2088 group received LPS (2.5mg/kg) and ODN 2088 (50ug/20g), which were administered intraperitoneally twice a week. The study included six experimental groups: Control, EAM, EAM LPS, EAM+ODN Control, EAM+ODN 2088 and EAM LPS+ODN 2088. All mice were sacrificed for further examinations at the inflammatory peak of EAM on Day 21 after immunization. All animal studies were approved by the Animal Care and Utilization Committee of Fudan University.

\section{Cell culture and treatment}

Myocardial myoblast H9C2 was cultured in DMEM/F12 with 10\% fetal bovine serum (Gibco, Grand Island, NY). For detecting mitochondrial superoxide production, H9C2 was cultured with $10 \mathrm{ug} / \mathrm{mL}$ LPS for $24 \mathrm{~h}$ after pre-treatment with 10nM Mito-TEMPO (Enzo Life Sciences, Farmingdale, NY) for $1 \mathrm{~h}$, then incubated with $2.5 \mu \mathrm{M}$ MitoSOX ${ }^{\mathrm{M}}$ Red Mitochondrial Superoxide Indicator (Molecular Probes) for $10 \mathrm{~min}$, washed and mounted in warm buffer for imaging.

\section{Immunohistochemistry analysis}

The heart tissues were fixed with $4 \%$ formalin, embedded in paraffin and sectioned into $6 \mu \mathrm{m}$ thick slices. To evaluate the expression of TLR9 in myocardium, sections after antigen retrieval were incubated with monoclonal mouse anti-TLR9 antibodies (Abcam, Cambridge, MA, USA), followed by treatment with horseradish peroxidase-conjugated goat anti-mouse antibody. The reaction products were visualized using diaminobenzidine chromogen and counterstained with hematoxylin. Myocarditis severity was scored on hematoxylin and eosin stained sections using grades as described previously [24].

\section{Serum Troponin Determinations}

Mouse serum was collected from mice at the time of sacrifice in glass tubes and stored at $-80^{\circ} \mathrm{C}$ until use. The levels of cardiac troponin I were measured with an ELISA kit (Mouse Cardiac TnI, Ultra Sensitive; Life Diagnostics).

\section{Evaluation of apoptosis in tissue sections and cardiomyocytes}

DNA fragmentation was detected in situ with the use of terminal deoxynucleotidyl transferase dUTP nick end labelling (TUNEL), as described previously [25]. The hearts were fixed in 4\% paraformaldehyde, embedded in paraffin, cut into $6 \mu \mathrm{m}$ thick sections and treated as instructed in the In Situ Cell Death Detection kit (Roche Diagnostics GmbH, Mannheim, Germany). The nuclear density was determined via manual counting of the $4^{\prime}, 6$-diamidino-2-phenylindole (DAPI)-stained nuclei in five fields for each animal with a $\times 40$ objective, and the number of TUNEL-positive nuclei was determined by examining the entire section with the same power objective. The cardiac caspase- 3 activity was measured using a caspase colorimetric assay kit following the manufacturer's instructions (Chemicon, Temecula, CA, USA). The absorbance of the pnitroaniline cleaved by caspase was measured at $405 \mathrm{~nm}$ using a microplate reader (ELx800; BioTek Instruments, Winooski, VT, USA).

\section{Dihydroethidium (DHE) detection}

DHE staining was performed as described previously [26]. After being harvested, the heart tissues were embedded immediately in an optimum cutting temperature (OCT) compound and stored at $-80^{\circ} \mathrm{C}$. The unfixed frozen samples were cut into $6 \mu \mathrm{m}$ thick sections and placed on glass slides. $10 \mu \mathrm{mol} / \mathrm{L}$ DHE was 


\section{Cellular Physiology Cell Physiol Biochem 2017;42:713-728 \begin{tabular}{l|l} 
and Biochemistry Published $10.1159 / 000477889$ & $\begin{array}{l}\text { DO } 2017 \text { The Author(s). Published by S. Karger AG, Basel } \\
\text { www.karger.com/cpb }\end{array}$ \\
\hline
\end{tabular} \\ Wu et al.: Circulating Mitochondrial DNA in Experimental Autoimmune Myocarditis}

applied to each tissue section and the sections were covered with a coverslip. The slides were incubated in a light-protected humidified chamber at $37^{\circ} \mathrm{C}$ for $30 \mathrm{~min}$. The ethidium fluorescence (excitation at $490 \mathrm{~nm}$, emission at $610 \mathrm{~nm}$ ) was examined by fluorescence microscopy.

\section{Lipid peroxidation detection}

The frozen heart tissues were homogenized in $250 \mu$ of ice-cold $20 \mathrm{mM}$ Tris- $\mathrm{HCl}$ (pH7.4). After centrifugation, $200 \mu \mathrm{l}$ of supernatant were analyzed for lipid peroxidation products [malondialdehyde (MDA)/4- hydroxyalkenals (4-HNE)] using a lipid peroxidation assay kit (Calbiochem, Darmstadt, Germany), as described previously [26].

\section{Mitochondrial DNA quantification}

Blood was collected from mice at the time of sacrifice in EDTA tubes. Blood in EDTA tubes was immediately centrifuged at $1600 \mathrm{~g}$ for $10 \mathrm{~min}$ at $4^{\circ} \mathrm{C}$. Plasma was then stored at $-80^{\circ} \mathrm{C}$ until analysis. Circulating plasma DNA, myocardial tissue and rat H9C2 cell genomic DNA were extracted and purified separately using the QIAamp DNA Blood Mini Kit or DNeasy Blood \& Tissue Kit (Qiagen). MtDNA content was assessed by using real time PCR (RT-PCR). The primers for mouse mtDNA (mMito F, mMito R), mouse nuclear B2m (mB2m F, mB2m R) and H9C2 mtDNA (rMito F, rMito R), rat nuclear B2m(rB2m F, rB2m R) were used to amplify the respective products from plasma, tissue and cells (Table 1). RT-PCR was carried out in $20 \mu$ l of total reaction volume containing $6 \mu \mathrm{l} \mathrm{H} \mathrm{H}_{2} \mathrm{O}, 10 \mu \mathrm{l}$ SYBR $®$ Fast qPCR Mix (Takara Biotechnology), ROX Reference Dye $0.4 \mu \mathrm{l}, 0.8 \mu \mathrm{l}$ of each of the above mentioned $10 \mu \mathrm{M}$ primers, and $2 \mu \mathrm{l}$ DNA. RT-PCR was performed using the ABI PRISM 7500 Sequence Detection System (Applied Biosystems, Branchburg, New Jersey, USA) under the following conditions: an initiation step of denaturation for 10 minutes at $95^{\circ} \mathrm{C}$ is followed by a further step consisting of 40 cycles of 10 seconds of denaturation at $95^{\circ} \mathrm{C}$ and 30 seconds of annealing and extension at $60^{\circ} \mathrm{C}$, then melting at $95^{\circ} \mathrm{C}$ for $5 \mathrm{~s}, 65^{\circ} \mathrm{C}$ for $60 \mathrm{~s}$, and $95{ }^{\circ} \mathrm{C}$ continues (melt curve analysis: 1 cycle) and a last step of cooling at $40^{\circ} \mathrm{C}$ for $30 \mathrm{~s}$ [27]. Plasma mtDNA RT-PCR results were presented as the inverse of cycle threshold (CT) for gene amplification [22]. MtDNA copy numbers in cell and tissue were calculated using the following equation: relative copy number $=2^{\text {DCt }}(\mathrm{DCt}=\mathrm{Ct} \mathrm{B2m}-\mathrm{Ct}$ Mito) [28]. Endpoint PCR products amplified were performed on a 1\% agarose gel to confirm the specificity of the primers.

Real-time polymerase chain reaction (PCR) for gene expression

Total RNA was extracted from tissues using Trizol (Invitrogen, Carlsbad, CA, USA) and reverse transcribed into cDNA using the PrimeScript RT reagent kit (Takara Biotechnology, Dalian, China), according to the manufacturer's instructions. The mRNA levels of target genes were quantified using SYBR Green Master Mix (Takara Biotechnology) with the ABI PRISM 7500 Sequence Detection System (Applied

Table 1. Primers used for RT-PCR in the study

\begin{tabular}{llc}
\hline Accession number & Primer & Oligonucleotide sequence $\left(5^{\prime} \rightarrow 3^{\prime}\right)$ \\
\hline NC_005089.1 & mMito F1 & CGTACACCCTCTAACCTAGAGAAGG \\
& mMito R1 & GGTTTTAAGTCTTACGCAATTTCC \\
& mMito F2 & CTAGAAACCCGAAACCAAA \\
& mMito R2 & CCAGCTATCACCAAGCTCGT \\
& mMito F3 & CCTTGTTCCCAGAGGTTCAA \\
& mMito R3 & ATGCCGTATGGACCAACAAT \\
NC_000068.7 & mB2M F & GTGGTGCCAGCAGAGACTTA \\
& mB2M R & GGACAGTGGGTAGGGAACTG \\
NC_001665.2 & rMito F & CCGTCACCCTCCTCAAATTA \\
& rMito R & TGTAGGCCAGATGCTTTGTG \\
NC_005102.4 & rB2M F & CTGGCCACTGAGTTCACAGA \\
& rB2M R & GACGAGCATGCACTCCACTA \\
NM_031178.2 & TLR9 F & GAGAATCCTCCATCTCCCAAC \\
& TLR9 R & CCAGAGTCTCAGCCAGCAC \\
NM_008084.2 & GAPDH F & AGCTTGTCATCAACGGGAAG \\
& GAPDH R & TTTGATGTTAGTGGGGTCTCG \\
\hline
\end{tabular}




\section{Cellular Physiology Cell Physiol Biochem 2017;42:713-728 \begin{tabular}{l|l} 
DOI: 10.1159/000477889 & O 2017 The Author(s). Published by S. Karger AG, Basel \\
www.karger.com/cpb
\end{tabular} \\ Wu et al.: Circulating Mitochondrial DNA in Experimental Autoimmune Myocarditis}

Biosystems, Branchburg, New Jersey, USA). Each reaction was performed in duplicate and changes in relative gene expression normalized to GAPDH levels were determined using the relative threshold cycle method. The primer sequences are shown in Table 1.

\section{Western blot analysis}

The total lysates from heart tissue were immunoblotted and probed with primary antibodies against TLR-9 (Abcam, Cambridge, MA, USA) and glyceraldehyde 3-phosphate dehydrogenase (GAPDH) using an adaptation of a previously described protocol [29]. Densitometry was performed using the Image Pro Plus software (Media Cybernetics, Silver Spring, MD, USA).

Enzyme-linked immunosorbent assay (ELISA)

Mouse serum was collected from mice at the time of sacrifice in glass tubes and stored at $-80{ }^{\circ} \mathrm{C}$ until use. TNF- $\alpha$, IL-1 $\beta$ and IL- 6 were measured using ProcartaPlex® Multiplex Immunoassays (Ebioscience) according to manufacturer's instructions.

\section{Apoptosis assay by flow cytometry}

The amount of apoptosis in the cardiomyocytes was determined using the annexin V-EGFP/PI Apoptosis Detection Kit (Vazyme, Nanjing, China) according to the manufacturer's instructions. Briefly, H9c2 cell was treated with $10 \mathrm{ug} / \mathrm{mL}$ LPS for $24 \mathrm{~h}$ with or without pretreatment of $1 \mu \mathrm{g} / \mathrm{ml}$ ODN 2088 or ODN control for 5 hours, then stained with EGFP-conjugated annexin V and PI for $10 \mathrm{~min}$ at room temperature. The percentage of positive cells collected from over 10,000 events was analyzed by a FACSCalibur system (BD BioSciences, San Jose, CA, USA).

\section{Statistics}

The data are presented as the means \pm SD unless indicated otherwise. The differences were evaluated using unpaired Student's t-tests between two groups when the data were normally distributed and group variances were equal. The Mann-Whitney rank sum test was used when the data were not normally distributed or if group variances were unequal. A one-way analysis of variance (anova) was used for multiple comparisons followed by a post-hoc Tukey's procedure for multiple range tests when the data were normally distributed and the group variances were equal. The Kruskal-Wallis test, followed by Dunn's test, was used when the group data were not normally distributed or if the group variances were unequal. GraphPad Prism version 6.0 software was used for statistical analyses, and the statistical significance was set at $\mathrm{P}<0.05$.

\section{Results}

TLR4 activation aggravated cardiac inflammation and injury in EAM

To investigate the effect of TLR4 activation on inflammatory severity after EAM induction, firstly, protein expression in the myocardium of mice was performed. Induction of EAM resulted in an increased expression of TLR4, and simultaneously given LPS treatment at a dose of $2.5 \mathrm{mg} / \mathrm{kg}$ further added the trend compared with EAM alone (Fig. 1A and B). Stained by hematoxylin and eosin of hearts, EAM group presented an evident inflammatory cell infiltration compared with control group as showed in Fig. 1C. However, LPS treatment more significantly amplified the response in EAM, and the gross severity scores were also obviously higher than that in EAM group (Fig. 1D).

Induction of EAM results in an increased expression of adhesion molecules and proinflammatory cytokines which are collectively involved in the initiation and progression of EAM [1]. Compared with control mice, EAM mice showed an increased expression of TNF- $\alpha$, IL- 6 and IL-1 $\beta$ in serum, which was further augmented by TLR4 activation (Fig. 1EG). Obvious inflammation condition mediated by inflammatory cells and cytokines within the heart leads to increased tissue injury [1]. Next we detected the cardiac specific serum Troponin I (TnI) in serum and found that TLR4 activation more significantly raised the level of TnI induced in EAM (Fig. 1H). These results indicate that TLR4 activation aggravated cardiac inflammation and injury in EAM. 


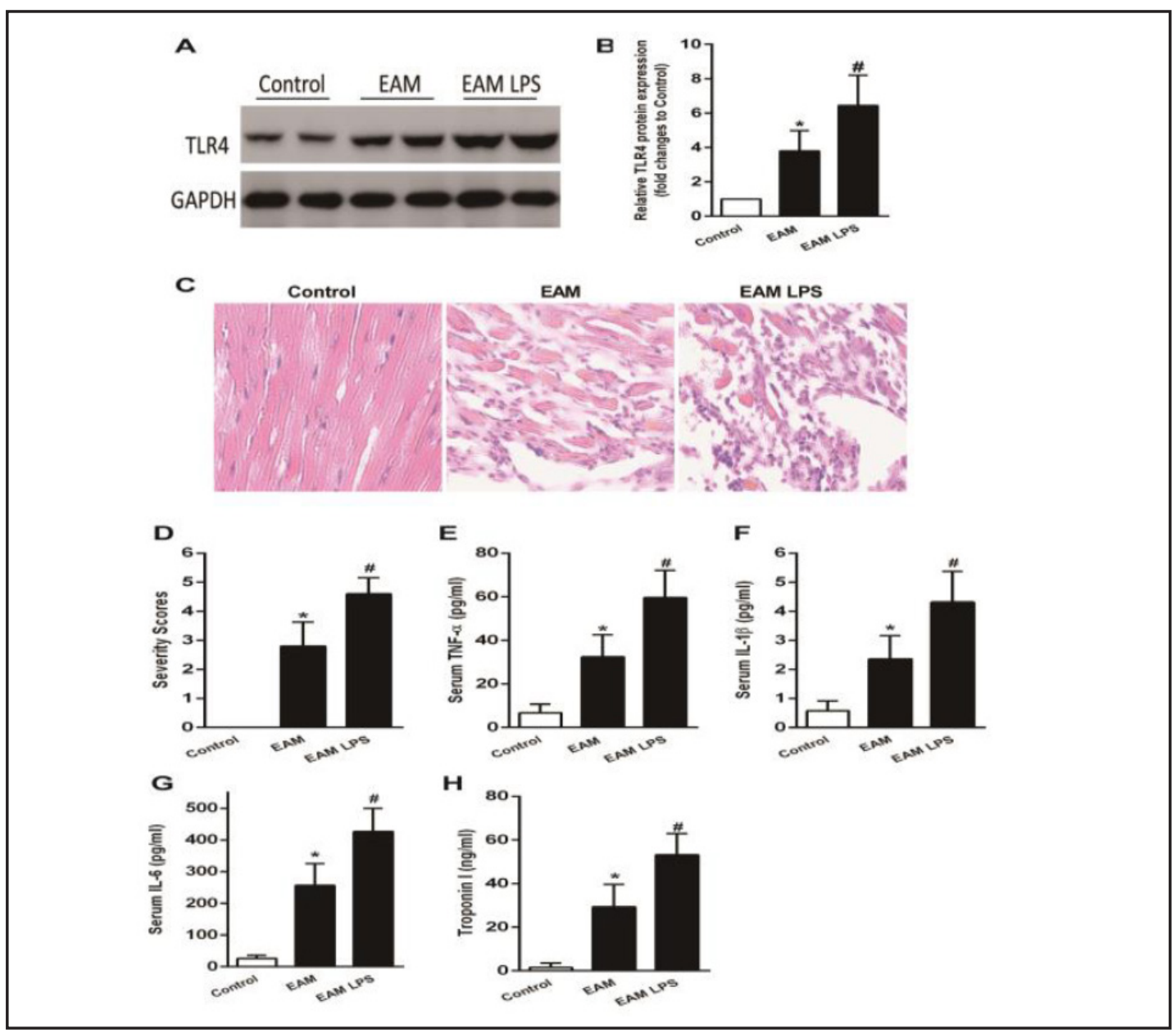

Fig. 1. TLR4 activation aggravated cardiac inflammation and injury in EAM. Representative western blot (A) and quantitative analysis (B) of TLR4 expression in myocardium ( $n=6)$. (C) Representative illustrations of inflammatory cell infiltration in cardiac sections taken on day 21 by H\&E staining (40x). (D) Myocarditis severity scores in the heart sections $(n=6)$. Serum levels of TNF- $\alpha(E)$, IL-1 $\beta(F)$, IL-6(G) were measured by Multiplex Immunoassays( $\mathrm{n}=6-8)$. (H)Troponin I serum levels are indicated $(\mathrm{n}=5-6) .{ }^{*} \mathrm{p}<0.05$ versus Control, \# $\mathrm{p}<0.05$ versus EAM.

\section{TLR4 activation induced cardiomyocytes apoptosis and oxidative stress in EAM}

Apoptosis has been proposed to be an important mechanism for myocardial injury in EAM [1]. As shown in Fig. 2A and B, the representative TUNEL-stained sections demonstrated drastically more apoptotic cells in EAM LPS group compared with EAM group. Furthermore, TLR4 activation also greatly increased the activation of caspase-3 (Fig. 2C), as determined by a caspase colorimetric assay of myocardium tissue in EAM mice. As an excessive ROS is a hallmark of cardiomyocyte apoptosis mediated by oxidative stress, we investigated whether the increased apoptosis upon TLR4 activation was also associated with a higher level of ROS in vivo. As shown in Fig. 3 A and B, ROS stress in EAM mice significantly increased compared with control mice, and LPS treatment further intensified ROS production in myocardial tissue of EAM mice. Consistent with the above result, the ROS-producing activity of cardiac homogenates in EAM mice, as evaluated with lipid peroxides (malondialdehyde and 4-hydroxyalkenal), was also significantly enhanced after LPS stimulation (Fig. 3C). These results suggest that TLR4 activation may promote cardiomyocyte apoptosis by inducing ROS production in EAM. 
Fig. 2. TLR4 activation induced cardiomyocytes apoptosis in EAM. (A) Apoptotic cell nuclei in cardiac sections were evaluated by terminal deoxynucleotidyl transferase dUTP nick end labelling (TUNEL) staining (green), and total nuclei by $4^{\prime}, 6$-diamidino-2-phenylindole

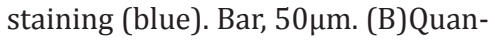
titative analysis of percentage of cardiomyocytes undergoing apoptosis in vivo $(\mathrm{n}=5-6)$. (C)Caspase-3 activity in myocardium was assessed $(\mathrm{n}=6) .{ }^{*} \mathrm{p}<0.05$ versus Control, \# $\mathrm{p}<0.05$ versus EAM.

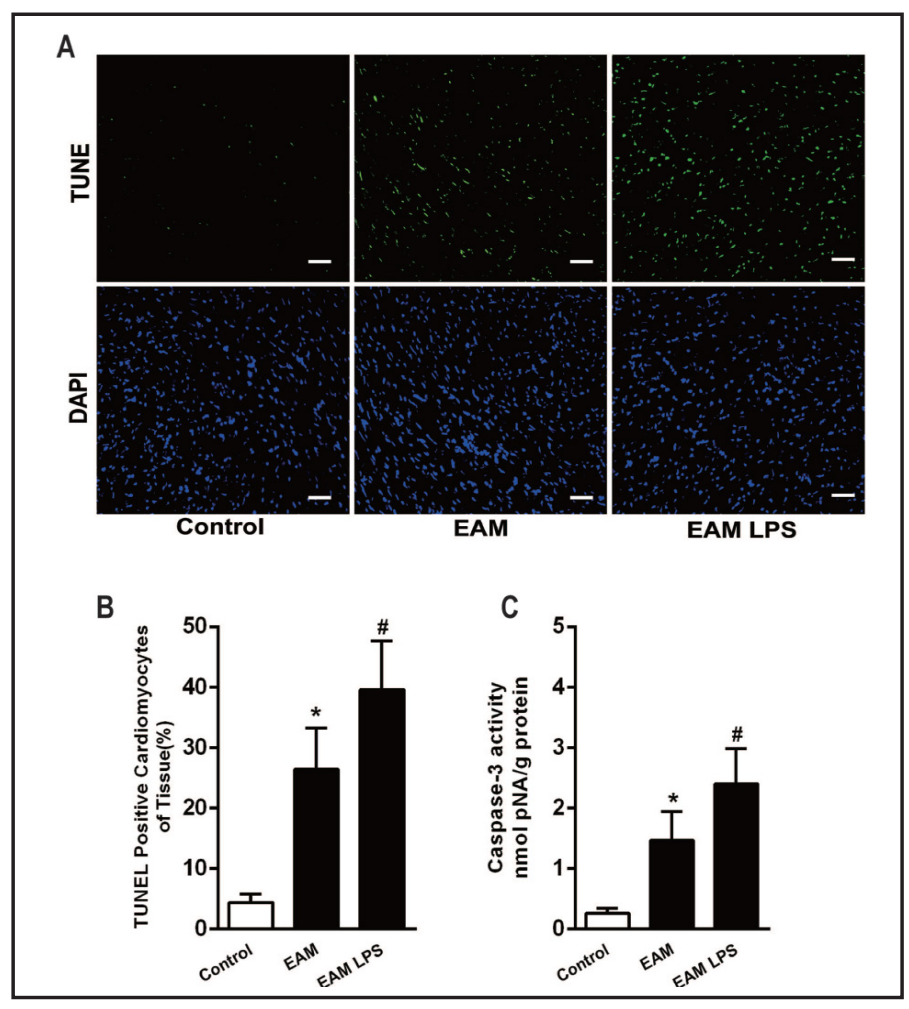

Fig. 3. TLR4 activation induced cardiac oxidative stress in EAM. (A)Reactive oxygen species (ROS) production in the cardiac sections was evaluated with dihydroethidium (DHE) staining. Bar, $20 \mu \mathrm{m}$. (B) Quantitative analysis of ROS, as normalized to Control $(n=5-6)$. (C)Malonaldehyde+4hydroxy- alkenals(MDA+4HAE)contents in myocardium were evaluated with the lipid peroxidation detection $(\mathrm{n}=$ 6). ${ }^{*} \mathrm{p}<0.05$ versus Control, \# $\mathrm{p}<0.05$ versus EAM.

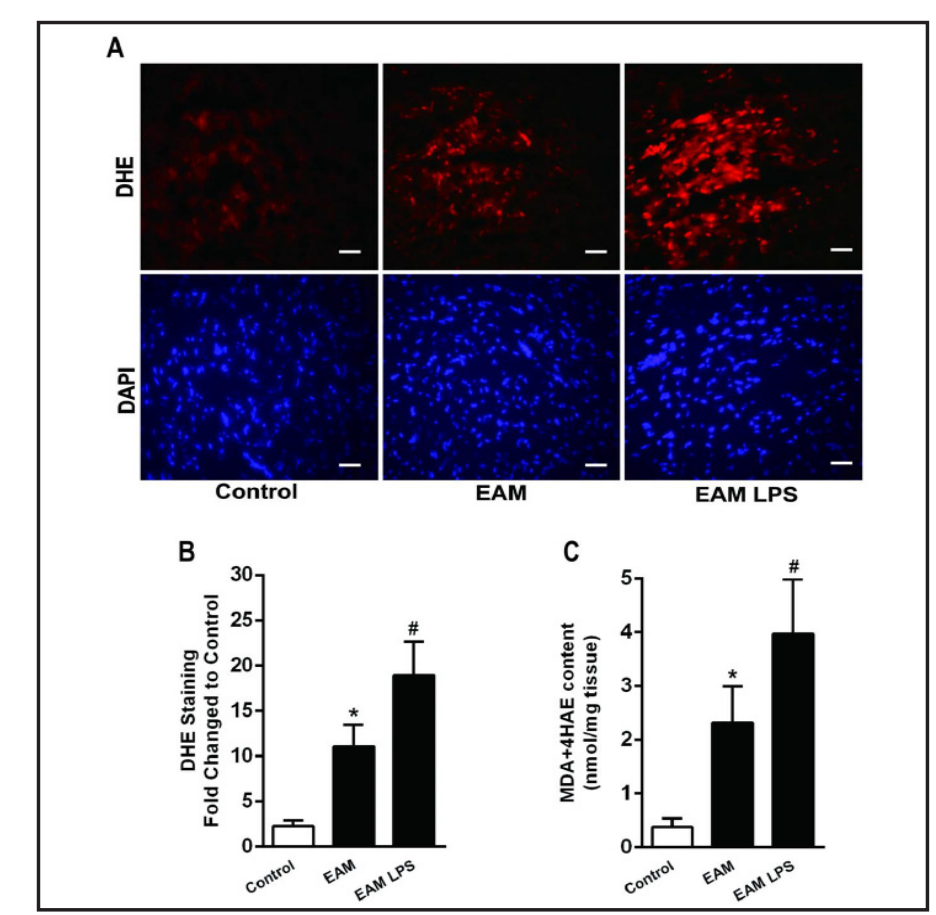

Circulating mtDNA level was increased in EAM and aggravated by TLR4 stimulation

TLR4 activation has been showed to contribute to inflammation response and tissue injury by inducing mitochondrial dysfunction, which often accompanies the release of mitochondrial components including mtDNA $[14,30]$. As an important newly found PAMP, circulating mtDNA level was investigated in EAM as well as after TLR4 activation. Relative mtDNA level in plasma of each group was quantified by RT-PCR. Firstly, to design a primer which does not co-amplify nuclear DNA, we searched for similar sequences between the mouse nuclear genome reference sequence and mitochondrial genome sequence (accession 
Fig. 4. TLR4 activation promoted cardiomyocytes mtDNA damage and increased circulating mtDNA level. (A) The first red line representing the mitochondrial genome sequence accession number NC_005089.1, was blasted against the reference sequence of the mouse genome using Nucleotide Blast, and below fragments of varying length are regions of the nuclear genome matched with mitochondrial genome. (B) The result showed no statistic difference for RT-PCR of the same genomic DNA from HL-1 or MEF with three pairs of designed primers.HL-1,mouse atrial cardiac muscle cells; MEF, mouse embryonic fibroblast. (C) Quantification of circulating plasma mtDNA of EAM mice, as measured by RT-PCR. $1 / \mathrm{Ct}$ denotes the reciprocal of the count where the sequence is detected, as a direct indication of mtDNA level ( $n=6-8)$. (D) Quantification of circulating plasma mtDNA, as measured

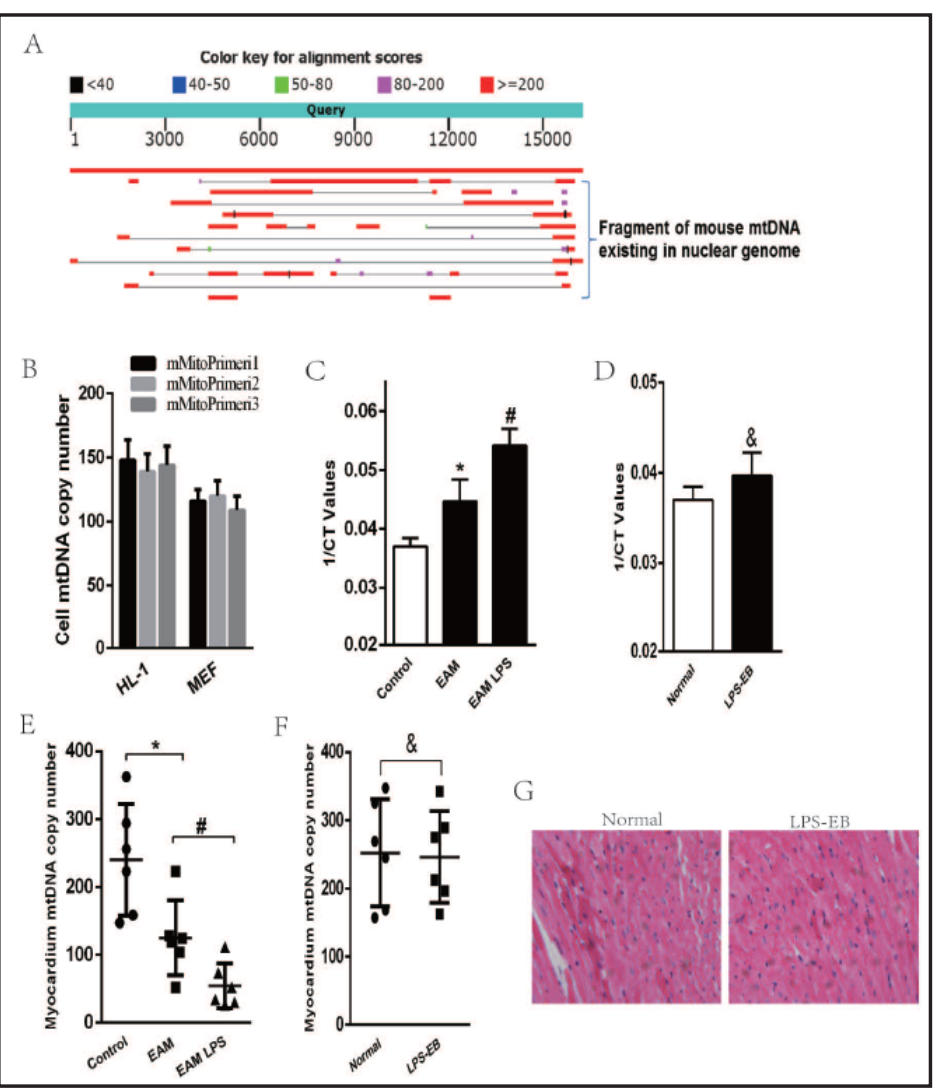
by RT-PCR from plasma of mice treated with a low dose of LPS-EB (n=6). (E) MtDNA content in myocardium of EAM mice was calculated relative to nuclear genome $(n=6)$. (F) MtDNA content in myocardium of mice treated with a low dose of LPS-EB was calculated relative to nuclear genome $(n=6)$. (G) Representative illustrations of inflammatory cell infiltration in cardiac sections of mice treated with PBS or with a low dose of LPS-EB by H\&E staining (20X). * $\mathrm{p}<0.05$ versus Control, \# $\mathrm{p}<0.05$ versus EAM, \& $\mathrm{p}>0.05$ versus Normal mice.

number NC_005089.1) using blast (https://blast.ncbi.nlm.nih.gov/Blast.cgi), showing that many regions of the mouse mitochondrial genome have high sequence identity with regions situated in the nuclear genome (Fig. 4A). Using this approach, we found that a special mitochondrial sequence between position 200-3000 of the mouse mitochondrial genome, the frequency and length of similar nuclear sequence were few, so we used this mitochondrial sequence to design primers $\mathrm{mMitoF}$ and $\mathrm{mMitoR}$, and three pairs of primers were designed (Table 1). Furthermore, with the same samples, the results of RT-PCR for mtDNA showed consistent with each other (Fig. 4B), confirming the specificity of the primers, and we chose mMitoF1 and mMitoR1 for the following experiment. Fig. 4C showed that mtDNA copy number in circulation was significantly increased in EAM, and TLR4 activation resulted in a higher elevation after that. To confirm whether the higher elevation of circulating mtDNA in EAM LPS group was caused by the TLR4 activation directly, we further observed the circulating mtDNA level in normal mice treated with the same dose of LPS-EB alone, and found that circulating mtDNA level was just slightly increased with no statistical difference (Fig. 4D), showing that elevated circulating mtDNA of EAM LPS group was mainly owing to the more severe lesion mediated by TLR4 activation. To ascertain where this elevated circulation mtDNA comes from in EAM, we measured the mtDNA content in myocardium, which often indicates mtNDA damage [30]. As showed in Fig. 4E, mtDNA copy number normalized to nuclear DNA holds an inverse relationship with circulation in EAM and EAM LPS group compared with control group. Interesting, we also found that a low dose of LPS treatment alone did not cause a reduce of mtDNA copy number in myocardium as compared with control group(Fig. 4F), which was consistent with the result that the inflammatory cells 
Fig. 5. ROS was involved mtDNA damage in H9C2 cell treated with LPS. (A) Representative images of mtROS measured by MitoSox Red fluorescence in $\mathrm{H} 9 \mathrm{C} 2$ cells. (B) Quantitative analysis of mtROS from H9C2 induced by LPS with or without TEMPO, as normalized to Control $(n=4-5)$. (C) MtDNA content in H9C2 was calculated relative to nuclear genome $(n=4-5) . \& p>0.05$ versus Control, ${ }^{*} \mathrm{p}<0.05$ versus Control, \# $\mathrm{p}<0.05$ versus LPS group.

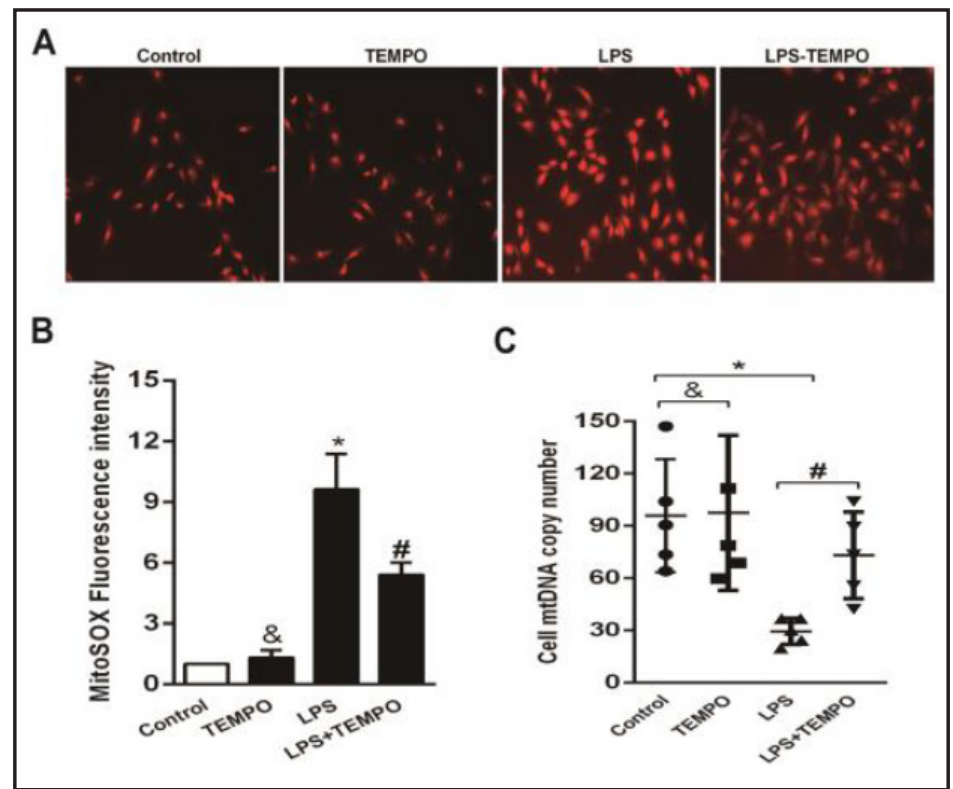

Fig. 6. TLR9 expression was increased in EAM and promoted TLR4 stimulation mediated cell apoptosis in vitro. (A) Immunohistochemistry $(20 \times)$ of cardiac sections showed increased expression of TLR9 in EAM and EAM LPS groups. (B-D) TLR9 expression in heart was examined by western blot and RT-PCR analyses ( $\mathrm{n}=6)$. (E and F)TLR9 inhibition decreased LPS induced H9C2 cell apoptosis with flow cytometry $(n=4-$ 5). ${ }^{*} \mathrm{p}<0.05$ versus Control, \# $\mathrm{p}<0.05$ versus EAM or LPS group, $\& \mathrm{p}>0.05$ versus LPS group.

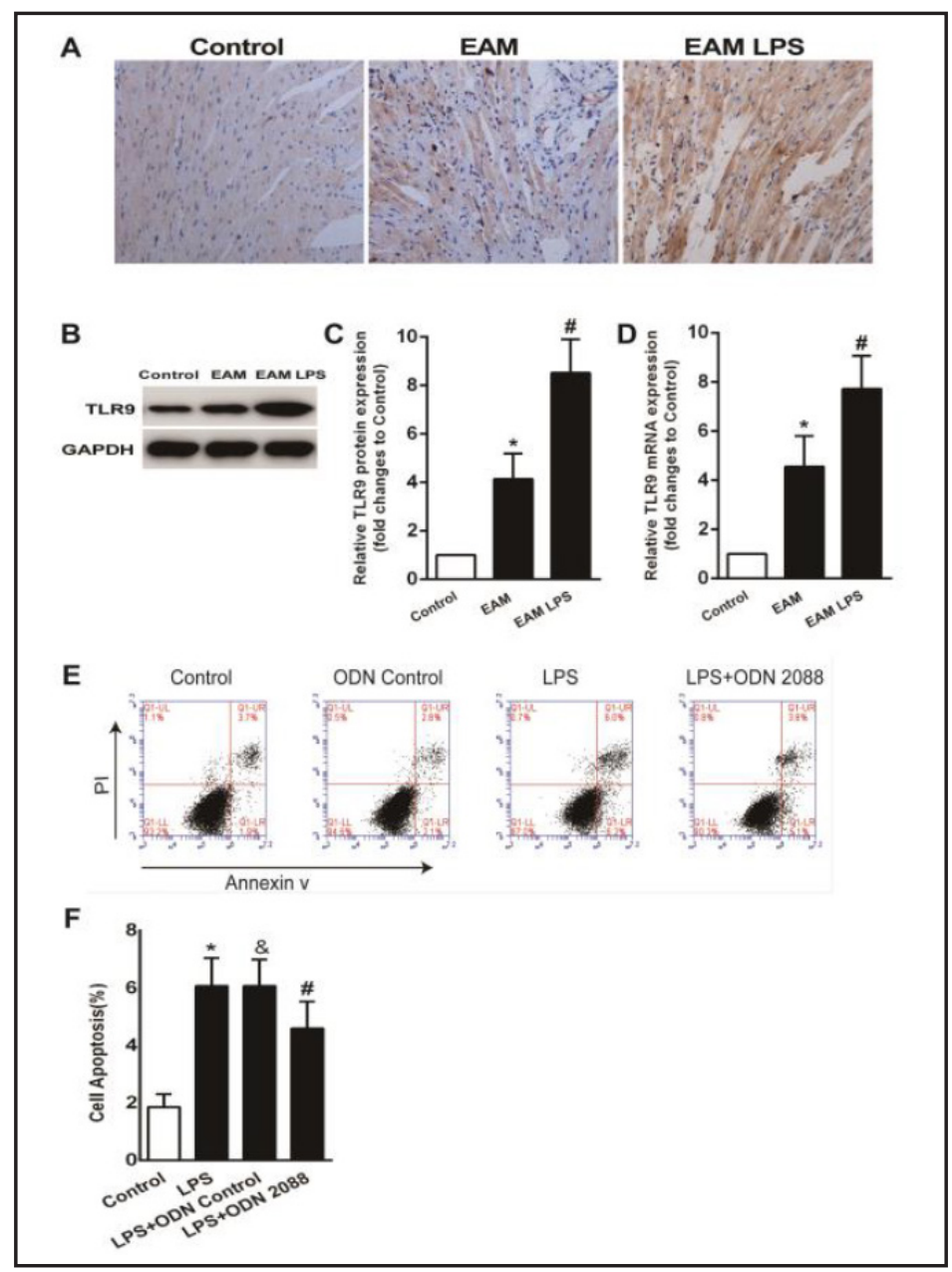

infiltration was not increased when directly giving a low dose of LPS to normal mice (Fig. $4 G)$. These results imply that increased circulating mtDNA may be released from injured cardiac tissue.

\section{KARGER}




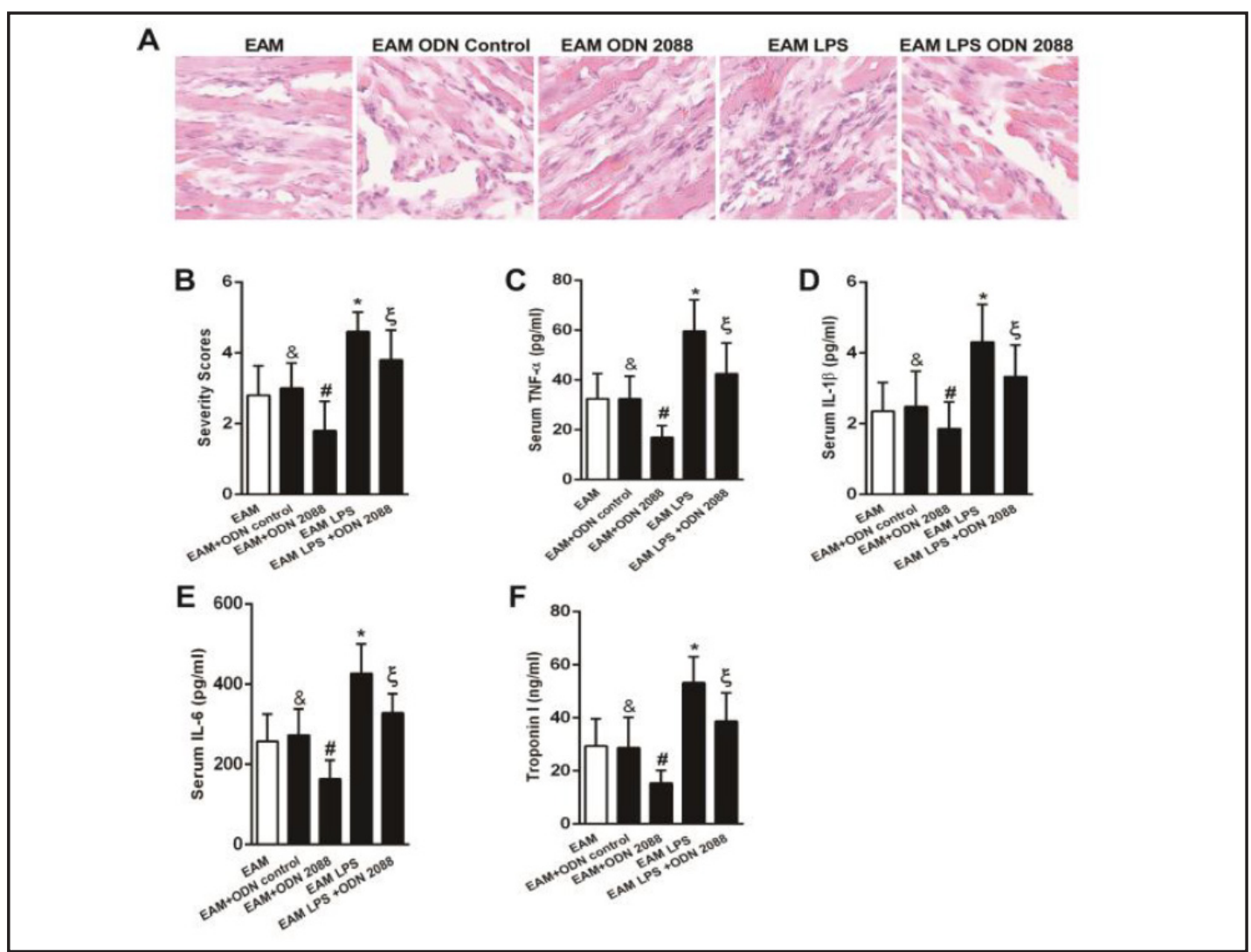

Fig. 7. TLR9 antagonist ODN2088 ameliorates TLR4 mediated cardiac inflammation and injury in EAM. (A) Representative illustrations of inflammatory cell infiltration in cardiac sections taken on day 21 by H\&E staining (40x). (B) Myocarditis severity scores in the heart sections $(n=6)$. Serum levels of TNF- $\alpha(C)$, IL$1 \beta(D)$, IL-6(E) were measured by Multiplex Immunoassays(n=6-8). (F) Troponin I serum levels are indicated $(n=5-6) . \& p>0.05$ versus EAM, \# $p<0.05$ versus EAM, ${ }^{*} p<0.05$ versus Control, $\xi p<0.05$ versus EAM LPS.

The above results showed an obviously increased ROS stress in EAM as well as EAM LPS group, which had been reported to damage mtDNA and promote mtDNA secretion $[21,31]$. Next, we further explored the role of mitochondrial ROS stress in LPS mediated mtDNA damage with H9C2 cell. Consistent with previous study, LPS stimulation significantly increased mitochondrial ROS produce, which could be blocked by TEMPO (Fig. 5A and B). Compared with control, TLR4 activation led to mtDNA damage, as demonstrated by an obvious mtDNA copy number reduction in H9C2. However, the damage was inhibited after mitochondrial ROS produce suppressed by TEMPO (Fig. 5C). These results altogether suggest that TLR4 activation may promote cardiomyocytes mtDNA damage and increase circulating mtDNA level by inducing ROS stress.

TLR9 expression was increased in EAM and promoted TLR4 activation mediated cell apoptosis

Studies have showed that mtDNA is released into circulation upon tissue injury and is able to induce systemic inflammation and cell apoptosis through TLR9, a key ligand of mtDNA [14, 22]. So we detected the TLR9 expression of myocardial tissue to validate the role of mtDNA mediated inflammation and tissue injury in EAM. Compared with control mice, EAM heart showed an elevated expression of TLR9 (Fig. 6A), which was further increased when TLR4 was activated by LPS. This result was also confirmed by western blotting and RTPCR (Fig. 6B-D). To investigate if TLR9 was involved in cardiomyocytes apoptosis mediated by TLR4 activation, we used a TLR9 special inhibitor (ODN 2088) to block TLR9 function before LPS stimulation in H9C2. As showed in Fig. 6E and F, compared to control group, ODN 


\section{Cellular Physiology Cell Physiol Biochem 2017;42:713-728 \begin{tabular}{l|l} 
DOI: 10.1159/000477889 & O 2017 The Author(s). Published by S. Karger AG, Basel \\
www.karger.com/cpb
\end{tabular} \\ Wu et al.: Circulating Mitochondrial DNA in Experimental Autoimmune Myocarditis}

Fig. 8. A proposed model for increased circulating mtDNA promoting TLR4 mediated cardiac inflammation and injury in EAM. See discussion for details. Mito, mitochondrial.

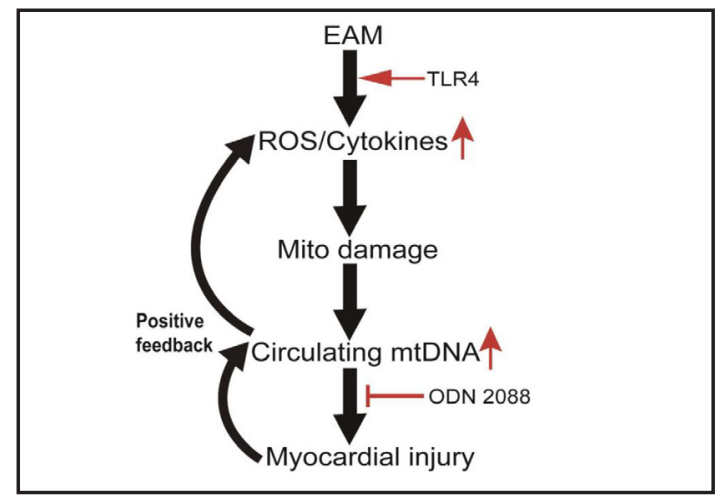

2088 reduced the percent of apoptosis induced by LPS stimulation. From these results, it can be concluded that the circulating mtDNA may mediate cardiac inflammation and tissue injury in EAM via TLR9.

TLR9 antagonist ODN2088 ameliorated EAM as well as TLR4 activation mediated cardiac inflammation and injury

Based on above findings, we further blocked mtDNA ligand TLR9 using ODN 2088 to observe if increased circulation mtDNA played a role in EAM as well as TLR4 activation mediated cardiac inflammation and lesion. Compared with ODN control group, we found that ODN 2088 significantly alleviated inflammatory cell infiltration and decreased gross severity scores in EAM. Moreover, simultaneously giving ODN 2088 in EAM LPS group also showed a mitigatory inflammation response (Fig. 7A and B).

TNF- $\alpha$, IL- 6 and IL-1 $\beta$ in serum were distinctly increased in EAM and EAM LPS groups, which can be lowered after ODN 2088 treatment in both groups(Fig. 7C-E). Finally, as showed in Fig. 7F, the cardiac specific serum Troponin I (TnI) in serum was also obviously ameliorated with OND 2088 treatment groups. Taken together, increased circulating mtDNA combined with upregulated TLR9 expression may corporately contribute to EAM as well as TLR4 activation mediated cardiac inflammation and injury.

\section{Discussion}

In this study, we report for the first time the elevated circulating mtDNA was involved in EAM as well as TLR4 activation mediated cardiac inflammation and injury (Fig. 8). Our data demonstrated that TLR4 activation damaged mtDNA, increased cardiomyocytes apoptosis and ROS produce in myocardium, which were accompanied with elevated mtDNA level in circulation and increased expression of TLR9 in heart. Mechanistically, we showed that LPS stimulation induced mtDNA damage depended on ROS stress and promoted cardiomyocytes apoptosis by TLR9 in vitro. Furthermore, EAM and TLR4 mediated cardiac inflammation and injury were obviously ameliorated by TLR9 inhibition with ODN2088.

Current evidence has demonstrated that EAM is mainly mediated by the host inflammation and immune response, where TLR4 signaling is considered to be a major contributor by influencing the interaction between cardiac cells and immune cells $[1,5]$. Apart from inducing a pro-inflammatory phenotype on cardiac cells, TLR4 promotes dendritic cells (DCs) activation, which is critical for the expansion of autoreactive CD4 ${ }^{+} \mathrm{T}$ cells in EAM [32]. TLR4 activation induces two complex signaling pathways: MyD88-dependent and MyD88 independent pathways, activating many transcription factors including NF- $\kappa B$ and interferonregulatory factors (IRFs) [5]. Studies have also indicated that some other signaling pathways, including phosphatidylinositol 3-kinase (PI3K)/Akt and HIF-1 dependent non-canonical TLR4 signaling pathway, may serve as an endogenous negative feedback regulator of TLR4 signaling in myocardial inflammation, which possibly explains the inconsistency of the role 


\section{Cellular Physiology Cell Physiol Biochem 2017;42:713-728 \begin{tabular}{l|l|l} 
and BiOChemistry & $\begin{array}{l}\text { DOI: 10.1159/000477889 } \\
\text { Published online: June 14, } 2017\end{array}$ & $\begin{array}{l}\text { C } 2017 \text { The Author(s). Published by S. Karger AG, Basel } \\
\text { www.karger.com/cpb }\end{array}$
\end{tabular} \\ Wu et al.: Circulating Mitochondrial DNA in Experimental Autoimmune Myocarditis}

of TLR4 in EAM $[5,33]$. In this study, we found that LPS mediated TLR4 activation increased circulating mtDNA level in EAM, which was associated with cardiac inflammation and injury. Increasing evidence proved that impaired mitochondrial function and mtDNA damage significantly led to inflammation and oxidative stress mediated diseases $[10,13]$. MtDNA released from dysfunctional mitochondria appeared to function as an important mediator in inflammatory diseases $[13,17]$. In LPS stimulation induced sepsis model, mitochondrial dysfunction and increased circulating mtDNA tightly related to organ inflammation and injury severity [16]. Studies showed that inflammatory cytokines, especially TNF- $\alpha$, could undermine mitochondrial function, and contribute to the secretion of mitochondrial content when inducing cells necrosis $[34,35]$. So the upregulated inflammatory cytokines in our EAM model may also aggravate the myocardium mtDNA damage and elevate circulating mtDNA level. In this study, TLR4 activation may significantly promote mitochondrial dysfunction, as showed by decreased mtDNA copy number in myocardium, which then led to the increased circulating mtDNA level. Acting as a new important inflammatory mediator, mtDNA may also play a role in EAM transition to DCM, which deserves further investigation [36].

Mounting evidence has revealed that mtDNA plays a crucial role during sterile inflammation in cardiovascular diseases [11]. MtDNA was showed to skew endotheliocytes and cardiomyocytes to an inflammatory feature and involved in atherosclerosis, hypertension, myocarditis and dilated cardiomyopathy induced by pressure overload [21, $22,36]$. MtDNA can provoke the immune response directly via the activation of TLR9, and the following NF- $\kappa \mathrm{B}$ signaling increases the expression of other pro-inflammatory cytokines, such as TNF- $\alpha$, IL- 6 and IL-1 $\beta[12,20,22]$. Nakahira et al showed that increased mitochondria reactive oxygen species (mROS) and NLRP3 activation in ATP or LPS stimulated macrophages promoted the release of mtDNA into the cytosol, which in turn activated NLRP3 inflammasome and mediated the secretion of IL-1 $\beta$ and IL-18, ultimately participated in the induction of inflammatory disease [12]. Our study presented that lowering ROS level could inhibit LPS mediated mtDNA damage in cardiomyocytes, which was consistent with the study that peroxyauraptenol(PXT) significantly inhibited inflammation and NLRP3 inflammasome in LPS activated macrophages by preventing ROS generation and the release of mtDNA [37]. MtDNA can also directly induce cell apoptosis by targeting TLR9, as showed in podocyte, HUVECs and cardiomyocytes $[21,23,38]$. In our EAM model, TLR9 expression in myocardium was obviously increased. Moreover, the level was further upregulated by TLR4 activation, which is consistent with the study showing that cardiac TLR9 expression was significantly increased in acute phase of CVB3-induced myocarditis [39]. Interesting, we showed that TLR9 was involved in TLR4 mediated cardiomyocytes apoptosis in vitro. Furthermore, with ODN2088, an antagonist of TLR9, cardiac inflammation and injury was obviously suppressed in EAM and EAM LPS group. Altogether, our study indicated that LPS mediated TLR4 activation increased circulating mtDNA level via inducing ROS stress, which with upregulated TLR9 corporately contributed to cardiac inflammation and injury in EAM.

It is reasonable that elevated circulating mtDNA could further aggravate the inflammatory response and cause cardiac injury in EAM, but the source of which remains largely unknown $[11,36]$. In our EAM model, elevated circulating mtDNA may result from decreased mtDNA copy number in myocardium [13], as demonstrated by the results of cardiomyocytes treated with LPS in vitro. Stress stimulus or DNase II knockdown can stimulate mtDNA release and activate TLR9 to mediate inflammatory response in HUVECs and cardiomyocytes $[21,36]$. Besides, studies showed that the mtDNA level in circulating monocytes was decreased in patients with obstructive sleep apnea, peritoneal dialysis and CKD [40-42]. Furthermore, activated neutrophils, macrophages and platelets have been proved to release mtDNA and may also contribute to the elevated mtDNA in circulation [12, 19, 43]. We also showed that circulating mtDNA was slightly increased when giving LPS-EB alone to normal mice, as existing an obvious inflammatory response in EAM mice, so it should not be ignored that other cells, especially immune cells, may also involve in elevated circulating mtDNA in EAM. Under various stress conditions, noxious stimuli damaged mitochondria and resulted 


\section{Cellular Physiology Cell Physiol Biochem 2017;42:713-728 \\ \begin{tabular}{l|l} 
and Biochemistry Published online: June 14, 2017 & $\begin{array}{l}\text { (c) 2017 The Author(s). Published by S. Karger AG, Basel } \\
\text { www.karger.com/cpb }\end{array}$ \\
\hline
\end{tabular} \\ Wu et al.: Circulating Mitochondrial DNA in Experimental Autoimmune Myocarditis}

in mitochondrial fragmentation; studies have showed that LPS, TNF- $\alpha$ and ROS stimulation promoted cell apoptosis simultaneously with fragmented mitochondrial accumulation [44]. In TNF- $\alpha$ treated c-Flip -/- MEFs, fragmented mitochondria engulfed by vacuoles originating from the plasma membrane were released into the extracellular spaces not in an autophagy, but an actin polymerization dependent manner [45]. However, in LPS stimulated hepatocytes and MEFs, the pharmacological inhibition of autophagy by 3MA or atg5 deletion blocked the secretion of mitochondrial constituents [46]. These findings indicate that fragmented mitochondria containing damaged mtDNA can be secreted in a different mechanism, which is consistent with the observation that mtDNA release can be induced by mitochondrial permeability transition (MPT), as followed by mitochondrial fragmentation, osmotic swelling and rupture [47]. A recent study also demonstrated that secreted phospholipase A2 IIA (sPLA2-IIA) mediated hydrolysis of the mitochondrial membrane contributed to mtDNA excretion which promoted leukocyte activation and inflammatory response [48]. Furthermore, acetylcholine significantly attenuated calcium or ROS stress induced mitochondrial damage and mtDNA release [49]. Together, mtDNA may be released extracellularly following cellular stress and damage in a manner dependent on cell and stimulus type, and elucidating the detailed molecular mechanism by which mtDNA release may provide underlying targets to treat various inflammatory diseases caused by mitochondrial malfunction $[11,44]$.

MtDNA functions an important role in the development of different kinds of inflammatory diseases, such as RA, sterile SIRS, diabetes mellitus, Parkinson's disease and heart diseases $[11,13,17,50,51]$. Mitochondrial damage characteristic with membrane permeability transition, ROS production and insufficient mitophagy corporately leads to mtDNA secretion, which exerts potent activation effect on inflammation response $[12,47$, 52]. The increased mtDNA in circulation shows the extent of tissue injury, triggering a vicious cycle that inflammation induces mtDNA damage and secretion, then increased mtDNA in turn amplifies inflammation response and tissue injury $[17,53]$. Our study indicated that direct suppression of inflammation response or alleviation of mitochondrial ROS stress would diminish mtDNA damage and the secretion of mtDNA, which can significantly ameliorate the cardiac inflammation and injury in EAM. Furthermore, other studies targeting in mtDNA excretion or its ligand also acquired obviously beneficial results in reversing mtDNA mediated adverse effect $[36,54]$. Pretreatment or transfection with DNase I decreased the cytosolic mtDNA and impaired IL-1 $\beta$, IL-18 production in macrophages treated with LPS and ATP [12]. As an important ligand of mtDNA, TLR9 inhibition by chloroquine, ODN2088 or gene ablation also significantly alleviated the mtDNA mediated sterile inflammation response and tissue injury in blood vessel, lung and heart $[22,31,36]$, which was further demonstrated in our EAM model. These studies indicate that mtDNA presents a promising therapeutic target in inflammatory diseases.

The present study acknowledges a few limitations that should be stated. A major limitation is the absence of TLR4 inhibition or TLR4 deficient mice to further clearly observe the role of TLR4 activation in circulating mtDNA level in EAM. Although our results indicated ROS may be involved in mtDNA damage and release into circulation, the exact molecular mechanism still remains unclear, which impedes the targeted intervention of mtDNA in diseases and needs a further investigation. Our study did not include the clinical detect of circulating mtDNA in patients with myocarditis, the result of which may facilitate the understanding of pathophysiology and show diagnostic and therapeutic potential. In summary, the present study showed that the circulating mtDNA was involved in TLR4 mediated cardiac inflammation and injury in EAM. TLR4 activation induced mtDNA damage in myocardium, elevated mtDNA in circulation, moreover, upregulated cardiac TLR9 expression, which corporately contributed to TLR4 mediated cardiac inflammation and injury in EAM. These data imply mtDNA a potential therapeutic target for EAM. 


\section{Cellular Physiology Cell Physiol Biochem 2017;42:713-728 \begin{tabular}{l|l} 
DOI: 10.1159/000477889 & and Biochemistry \\
Published 2017 The Author(s). Published by S. Karger AG, Basel \\
www.karger.com/cpb
\end{tabular} \\ Wu et al.: Circulating Mitochondrial DNA in Experimental Autoimmune Myocarditis}

\section{Acknowledgements}

This work was supported by National Natural Science Foundation of China (81470496 to Bo Jin (81573710 to Haiming Shi) and Chinese Medicine Science Foundation of Shanghai Health and Family Planning Committee (2014JZ006A to Haiming Shi).

\section{Disclosure Statement}

The authors declare no conflict of interest.

\section{References}

1 Cihakova D, Rose NR: Pathogenesis of myocarditis and dilated cardiomyopathy. Adv Immunol 2008;99:95114.

2 Schaefer L: Complexity of danger: the diverse nature of damage-associated molecular patterns. J Biol Chem 2014;289:35237-35245.

3 Hofmann U, Ertl G, Frantz S: Toll-like receptors as potential therapeutic targets in cardiac dysfunction. Expert Opin Ther Targets 2011;15:753-765.

4 Satoh M, Nakamura M, Akatsu T, Iwasaka J, Shimoda Y, Segawa I, Hiramori K: Expression of Toll-like receptor 4 is associated with enteroviral replication in human myocarditis. Clin Sci (Lond) 2003;104:577584.

-5 Yang Y, Lv J, Jiang S, Ma Z, Wang D, Hu W, Deng C, Fan C, Di S, Sun Y, Yi W: The emerging role of Toll-like receptor 4 in myocardial inflammation. Cell Death Dis 2016;7:e2234.

6 Tada Y, Suzuki J: Oxidative stress and myocarditis. Curr Pharm Des 2016;22:450-471.

7 Zhao P, Wang J, He L, Ma H, Zhang X, Zhu X, Dolence EK, Ren J, Li J: Deficiency in TLR4 signal transduction ameliorates cardiac injury and cardiomyocyte contractile dysfunction during ischemia. J Cell Mol Med 2009;13:1513-1525.

8 Marty RR, Dirnhofer S, Mauermann N, Schweikert S, Akira S, Hunziker L, Penninger JM, Eriksson U: MyD88 signaling controls autoimmune myocarditis induction. Circulation 2006;113:258-265.

-9 Krysko DV, Agostinis P, Krysko O, Garg AD, Bachert C, Lambrecht BN, Vandenabeele P: Emerging role of damage-associated molecular patterns derived from mitochondria in inflammation. Trends Immunol 2011;32:157-164.

10 Cloonan SM, Choi AM: Mitochondria: commanders of innate immunity and disease? Curr Opin Immunol 2012;24:32-40.

-11 Konstantinidis K, Kitsis RN: Cardiovascular biology: Escaped DNA inflames the heart. Nature 2012;485:179-180.

12 Shimada K, Crother TR, Karlin J, Dagvadorj J, Chiba N, Chen S, Ramanujan VK, Wolf AJ, Vergnes L, Ojcius DM, Rentsendorj A, Vargas M, Guerrero C, Wang Y, Fitzgerald KA, Underhill DM, Town T, Arditi M: Oxidized mitochondrial DNA activates the NLRP3 inflammasome during apoptosis. Immunity 2012;36:401-414.

13 Malik AN, Czajka A: Is mitochondrial DNA content a potential biomarker of mitochondrial dysfunction? Mitochondrion 2013;13:481-492.

14 Zhang L, Deng S, Zhao S, Ai Y, Zhang L, Pan P, Su X, Tan H, Wu D: Intra-Peritoneal Administration of Mitochondrial DNA Provokes Acute Lung Injury and Systemic Inflammation via Toll-Like Receptor 9. Int J Mol Sci 2016;17:

-15 Simmons JD, Gillespie MN: Plasma nuclear and mitochondrial DNA levels in acute myocardial infarction patients. Coron Artery Dis 2015;26:286-288.

- 16 Timmermans K, Kox M, Scheffer GJ, Pickkers P: Plasma Nuclear and Mitochondrial DNA Levels, and Markers of Inflammation, Shock, and Organ Damage in Patients with Septic Shock. Shock 2016;45:607-612.

-17 Simmons JD, Lee YL, Mulekar S, Kuck JL, Brevard SB, Gonzalez RP, Gillespie MN, Richards WO: Elevated levels of plasma mitochondrial DNA DAMPs are linked to clinical outcome in severely injured human subjects. Ann Surg 2013;258:591-596; discussion 596-598. 


\section{Cellular Physiology Cell Physiol Biochem 2017;42:713-728

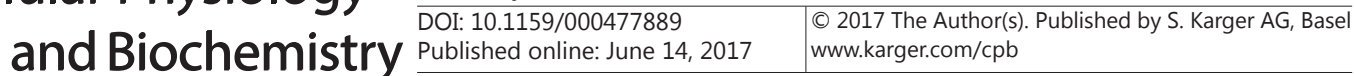 \\ Wu et al.: Circulating Mitochondrial DNA in Experimental Autoimmune Myocarditis}

18 Verschoor CP, Loukov D, Naidoo A, Puchta A, Johnstone J, Millar J, Lelic A, Novakowski KE, Dorrington MG, Loeb M, Bramson JL, Bowdish DM: Circulating TNF and mitochondrial DNA are major determinants of neutrophil phenotype in the advanced-age, frail elderly. Mol Immunol 2015;65:148-156.

19 Lood C, Blanco LP, Purmalek MM, Carmona-Rivera C, De Ravin SS, Smith CK, Malech HL, Ledbetter JA, Elkon KB, Kaplan MJ: Neutrophil extracellular traps enriched in oxidized mitochondrial DNA are interferogenic and contribute to lupus-like disease. Nat Med 2016;22:146-153.

20 Gu X, Wu G, Yao Y, Zeng J, Shi D, Lv T, Luo L, Song Y: Intratracheal administration of mitochondrial DNA directly provokes lung inflammation through the TLR9-p38 MAPK pathway. Free Radic Biol Med 2015;83:149-158.

21 Ding Z, Liu S, Wang X, Khaidakov M, Dai Y, Mehta JL: Oxidant stress in mitochondrial DNA damage, autophagy and inflammation in atherosclerosis. Sci Rep 2013;3:1077.

-22 McCarthy CG, Wenceslau CF, Goulopoulou S, Ogbi S, Baban B, Sullivan JC, Matsumoto T, Webb RC: Circulating mitochondrial DNA and Toll-like receptor 9 are associated with vascular dysfunction in spontaneously hypertensive rats. Cardiovasc Res 2015;107:119-130.

23 Bliksoen M, Mariero LH, Torp MK, Baysa A, Ytrehus K, Haugen F, Seljeflot I, Vaage J, Valen G, Stenslokken KO: Extracellular mtDNA activates NF-kappaB via toll-like receptor 9 and induces cell death in cardiomyocytes. Basic Res Cardiol 2016;111:42.

24 Hu F, Yan L, Lu S, Ma W, Wang Y, Wei Y, Yan X, Zhao X, Chen Z, Wang Z, Cheng B: Effects of 1, 25-Dihydroxyvitamin D3 on Experimental Autoimmune Myocarditis in Mice. Cell Physiol Biochem 2016;38:2219-2229.

25 Tao L, Bei Y, Lin S, Zhang H, Zhou Y, Jiang J, Chen P, Shen S, Xiao J, Li X: Exercise Training Protects Against Acute Myocardial Infarction via Improving Myocardial Energy Metabolism and Mitochondrial Biogenesis. Cell Physiol Biochem 2015;37:162-175.

-26 Wu B, Meng K, Ji Q, Cheng M, Yu K, Zhao X, Tony H, Liu Y, Zhou Y, Chang C, Zhong Y, Zhu Z, Zhang W, Mao X, Zeng Q: Interleukin-37 ameliorates myocardial ischaemia/reperfusion injury in mice. Clin Exp Immunol 2014;176:438-451.

-27 Malik AN, Czajka A, Cunningham P: Accurate quantification of mouse mitochondrial DNA without coamplification of nuclear mitochondrial insertion sequences. Mitochondrion 2016;29:59-64.

28 Malik AN, Parsade CK, Ajaz S, Crosby-Nwaobi R, Gnudi L, Czajka A, Sivaprasad S: Altered circulating mitochondrial DNA and increased inflammation in patients with diabetic retinopathy. Diabetes Res Clin Pract 2015;110:257-265.

29 Wang H, Bei Y, Lu Y, Sun W, Liu Q Wang Y, Cao Y, Chen P, Xiao J, Kong X: Exercise Prevents Cardiac Injury and Improves Mitochondrial Biogenesis in Advanced Diabetic Cardiomyopathy with PGC-1alpha and Akt Activation. Cell Physiol Biochem 2015;35:2159-2168.

-30 Suliman HB, Welty-Wolf KE, Carraway MS, Schwartz DA, Hollingsworth JW, Piantadosi CA: Toll-like receptor 4 mediates mitochondrial DNA damage and biogenic responses after heat-inactivated E. coli. FASEB J 2005;19:1531-1533.

-31 Zhang Q, Itagaki K, Hauser CJ: Mitochondrial DNA is released by shock and activates neutrophils via p38 map kinase. Shock 2010;34:55-59.

-32 Eriksson U, Ricci R, Hunziker L, Kurrer MO, Oudit GY, Watts TH, Sonderegger I, Bachmaier K, Kopf M, Penninger JM: Dendritic cell-induced autoimmune heart failure requires cooperation between adaptive and innate immunity. Nat Med 2003;9:1484-1490.

-33 Ha T, Hua F, Liu X, Ma J, McMullen JR, Shioi T, Izumo S, Kelley J, Gao X, Browder W, Williams DL, Kao RL, Li C: Lipopolysaccharide-induced myocardial protection against ischaemia/reperfusion injury is mediated through a PI3K/Akt-dependent mechanism. Cardiovasc Res 2008;78:546-553.

-34 Nystrom S, Antoine DJ, Lundback P, Lock JG, Nita AF, Hogstrand K, Grandien A, Erlandsson-Harris H, Andersson U, Applequist SE: TLR activation regulates damage-associated molecular pattern isoforms released during pyroptosis. EMBO J 2013;32:86-99.

-35 Maeda A, Fadeel B: Mitochondria released by cells undergoing TNF-alpha-induced necroptosis act as danger signals. Cell Death Dis 2014;5:e1312.

-36 Oka T, Hikoso S, Yamaguchi O, Taneike M, Takeda T, Tamai T, Oyabu J, Murakawa T, Nakayama H, Nishida K, Akira S, Yamamoto A, Komuro I, Otsu K: Mitochondrial DNA that escapes from autophagy causes inflammation and heart failure. Nature 2012;485:251-255. 


\section{Cellular Physiology Cell Physiol Biochem 2017;42:713-728 \begin{tabular}{l|l} 
DOI: 10.1159/000477889 & $\begin{array}{l}\text { O 2017 The Author(s). Published by S. Karger AG, Basel } \\
\text { www.karger.com/cpb }\end{array}$ \\
\hline
\end{tabular} \\ Wu et al.: Circulating Mitochondrial DNA in Experimental Autoimmune Myocarditis}

37 Chao LK, Lin CH, Chiu HW, Wong WT, Chiu HW, Tasi YL, Kuo YH, Chiu YC, Liu ML, Ho CL, Hua KF: Peroxyauraptenol Inhibits Inflammation and NLRP3 Inflammasome Activation by Inhibiting Reactive Oxygen Species Generation and Preserving Mitochondrial Integrity. J Agric Food Chem 2015;10.1021/ jf5054436

38 Bao W, Xia H, Liang Y, Ye Y, Lu Y, Xu X, Duan A, He J, Chen Z, Wu Y, Wang X, Zheng C, Liu Z, Shi S: Toll-like Receptor 9 Can be Activated by Endogenous Mitochondrial DNA to Induce Podocyte Apoptosis. Sci Rep 2016;6:22579.

-39 Riad A, Westermann D, Escher F, Becher PM, Savvatis K, Lettau O, Heimesaat MM, Bereswill S, Volk HD, Schultheiss HP, Tschope C: Myeloid differentiation factor-88 contributes to TLR9-mediated modulation of acute coxsackievirus B3-induced myocarditis in vivo. Am J Physiol Heart Circ Physiol 2010;298:H20242031.

-40 Tin A, Grams ME, Ashar FN, Lane JA, Rosenberg AZ, Grove ML, Boerwinkle E, Selvin E, Coresh J, Pankratz N, Arking DE: Association between Mitochondrial DNA Copy Number in Peripheral Blood and Incident CKD in the Atherosclerosis Risk in Communities Study. J Am Soc Nephrol 2016;27:2467-2473.

41 Yoon CY, Park JT, Kee YK, Han SG, Han IM, Kwon YE, Park KS, Lee MJ, Han SH, Kang SW, Yoo TH: Low Mitochondrial DNA Copy Number is Associated With Adverse Clinical Outcomes in Peritoneal Dialysis Patients. Medicine (Baltimore) 2016;95:e2717.

42 Kim YS, Kwak JW, Lee KE, Cho HS, Lim SJ, Kim KS, Yang HS, Kim HJ: Can mitochondrial dysfunction be a predictive factor for oxidative stress in patients with obstructive sleep apnea? Antioxid Redox Signal 2014;21:1285-1288.

43 Qin C, Gu J, Hu J, Qian H, Fei X, Li Y, Liu R, Meng W: Platelets activation is associated with elevated plasma mitochondrial DNA during cardiopulmonary bypass. J Cardiothorac Surg 2016;11:90.

-44 Green DR, Kroemer G: The pathophysiology of mitochondrial cell death. Science 2004;305:626-629.

-45 Nakajima A, Kurihara H, Yagita H, Okumura K, Nakano H: Mitochondrial Extrusion through the cytoplasmic vacuoles during cell death. J Biol Chem 2008;283:24128-24135.

-46 Unuma K, Aki T, Funakoshi T, Hashimoto K, Uemura K: Extrusion of mitochondrial contents from lipopolysaccharide-stimulated cells: Involvement of autophagy. Autophagy 2015;11:1520-1536.

-47 Orrenius S, Gogvadze V, Zhivotovsky B: Mitochondrial oxidative stress: implications for cell death. Annu Rev Pharmacol Toxicol 2007;47:143-183.

48 Boudreau LH, Duchez AC, Cloutier N, Soulet D, Martin N, Bollinger J, Pare A, Rousseau M, Naika GS, Levesque T, Laflamme C, Marcoux G, Lambeau G, Farndale RW, Pouliot M, Hamzeh-Cognasse H, Cognasse F, Garraud O, Nigrovic PA, Guderley H, Lacroix S, Thibault L, Semple JW, Gelb MH, Boilard E: Platelets release mitochondria serving as substrate for bactericidal group IIA-secreted phospholipase A2 to promote inflammation. Blood 2014;124:2173-2183.

-49 Lu B, Kwan K, Levine YA, Olofsson PS, Yang H, Li J, Joshi S, Wang H, Andersson U, Chavan SS, Tracey $\mathrm{KJ}$ : alpha7 nicotinic acetylcholine receptor signaling inhibits inflammasome activation by preventing mitochondrial DNA release. Mol Med 2014;20:350-358.

-50 Hsieh CJ, Weng SW, Liou CW, Lin TK, Chen JB, Tiao MM, Hung YT, Chen IY, Huang WT, Wang PW: Tissuespecific differences in mitochondrial DNA content in type 2 diabetes. Diabetes Res Clin Pract 2011;92:106110.

51 Hajizadeh S, DeGroot J, TeKoppele JM, Tarkowski A, Collins LV: Extracellular mitochondrial DNA and oxidatively damaged DNA in synovial fluid of patients with rheumatoid arthritis. Arthritis Res Ther 2003;5:R234-240.

-52 Duann P, Lianos EA, Ma J, Lin PH: Autophagy, Innate Immunity and Tissue Repair in Acute Kidney Injury. Int J Mol Sci 2016;17:

53 Palmai-Pallag T, Bachrati CZ: Inflammation-induced DNA damage and damage-induced inflammation: a vicious cycle. Microbes Infect 2014;16:822-832.

54 Yang XM, Cui L, White J, Kuck J, Ruchko MV, Wilson GL, Alexeyev M, Gillespie MN, Downey JM, Cohen MV: Mitochondrially targeted Endonuclease III has a powerful anti-infarct effect in an in vivo rat model of myocardial ischemia/reperfusion. Basic Res Cardiol 2015;110:3. 